\title{
A Note from the Editor
}

The past year has been an unusual and complex time to begin a new endeavor. As we saw the world shrink to the size of our own four walls, work and our relationship to it changed. Within this altered landscape, spaces of dialogue and collaboration take on even greater significance. This is exactly the type of space our online journal Mistral can and should be.

2020 was also a year in which people around the world took to the streets demanding greater justice and visibility for marginalized groups. We have become ever more cognizant of which stories have been allowed to be told and which have been systematically erased. Many of us are reconsidering the histories of our disciplines and institutions, our curricula and our canons. Mistral aims to contribute to this necessary process.

Taking its name from the pioneering Chilean poet and educator Gabriela Mistral, and also from a wind which shakes whatever comes into its path, the journal showcases research that examines Latin American women's contributions to intellectual history and the cultural sphere more broadly. In so doing, it addresses a void that has existed for too long within the field. Alongside cuttingedge academic articles, the journal's "Nuevos aires" section publishes creative critical works from leading Latin American women working inside and outside the academy. Mistral likewise presents other types of pieces, such as reviews of new books and exhibitions of interest, as well as translations of lesser-known works by Latin American women practitioners, collecting and foregrounding a recuperated body of work.

This inaugural issue brings together pieces by scholars and practitioners from across the US, Europe, and Latin America. Among them, David William Foster, Regents Professor of Spanish and Women and Gender Studies at Arizona State University, who sadly passed away in June 2020. David was an enthusiastic supporter of Mistral from its inception-sitting on our Editorial Board and submitting the journal's very first article, which we publish here today. Throughout his long career, David pioneered work in the field of gender and LGBTQ studies and we dedicate this inaugural issue to his memory.

Camilla Sutherland, Editor-in-Chief University of Groningen 